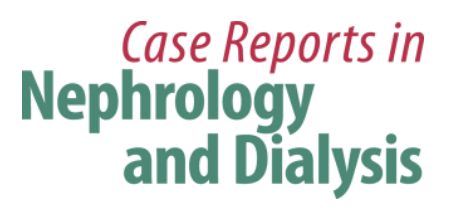

Case Rep Nephrol Dial 2018;8:1-9

DOI: 10.1159/000486159

Publisned online: January 19, 2018

(C) 2018 The Author(s)

Published by S. Karger AG, Basel

www.karger.com/cnd

This article is licensed under the Creative Commons Attribution-NonCommercial 4.0 International License (CC BY-NC) (http://www.karger.com/Services/OpenAccessLicense). Usage and distribution for commercial purposes requires written permission.

\title{
Exit Site Infection due to Mycobacterium chelonae in an Elderly Patient on Peritoneal Dialysis
}

\author{
Arata Hibi $^{a} \quad$ Takahisa Kasugai $^{a} \quad K^{2}$ eisuke Kamiya ${ }^{a, b} \quad$ Chiharu Ito $^{a}$ \\ Satoru Kominato ${ }^{a}$ Toshiyuki Miura $^{a}$ Katsushi Koyama ${ }^{a}$ \\ ${ }^{a}$ Division of Nephrology and Rheumatology, Department of Internal Medicine, Kariya \\ Toyota General Hospital, Kariya, Japan; ${ }^{b}$ Division of Nephrology and Rheumatology, \\ Department of Internal Medicine, Aichi Medical University Hospital, Nagakute, Japan
}

\section{Keywords}

Mycobacterium chelonae - Nontuberculous mycobacteria - Exit site infection · Peritoneal dialysis

\begin{abstract}
Nontuberculous mycobacteria (NTM) are rarely isolated from peritoneal dialysis (PD)associated catheter infections. However, NTM infection is usually difficult to treat and leads to catheter loss. Prompt diagnosis is essential for appropriate treatment. A 70-year-old Japanese man who had been on PD for 2 years and with a medical history of 2 episodes of exit site infections (ESIs) due to methicillin-resistant Staphylococcus aureus was admitted to the hospital due to suspected ESI recurrence. However, Gram staining of the pus revealed no gram-positive cocci. Instead, weakly stained gram-positive rods were observed after 7 days of incubation, which were also positive for acid-fast staining. Rapidly growing NTM Mycobacterium chelonae was isolated on day 14. Despite administering a combination antibiotic therapy, ESI could not be controlled, and catheter removal surgery was performed on day 21. Although PD was discontinued temporarily, the patient did not require hemodialysis, without
\end{abstract}




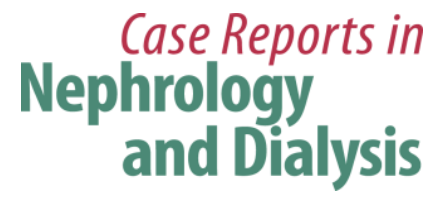

Case Rep Nephrol Dial 2018;8:1-9

DOI: $10.1159 / 000486159$

(c) 2018 The Author(s). Published by S. Karger AG, Basel www.karger.com/cnd

Hibi et al.: Exit Site Infection due to Mycobacterium chelonae in an Elderly Patient on Peritoneal Dialysis

any uremic symptoms. The catheter was reinserted on day 48, and PD was reinitiated on day 61. The patient was discharged on day 65. Antibiotic therapy was continued for 3 months after discharge, with no indications of recurrent infections observed. It is important to consider the risk of NTM infections in patients on PD. Acid-fast staining could be a key test for prompt diagnosis and provision of an appropriate treatment.

(C) 2018 The Author(s)

Published by S. Karger AG, Basel

\section{Introduction}

Peritoneal dialysis (PD)-associated catheter infection is one of the most serious complications in patients undergoing PD because it can lead to catheter loss or become fatal [1]. Although nontuberculous mycobacteria (NTM) are abundant in natural environments, such as soil and water, they are rarely isolated from patients with PD-associated catheter infections [2].

NTM refer to mycobacteria other than Mycobacterium tuberculosis. Rapidly growing NTM (RGNTM) are classified under class IV in the Runyon classification, and they usually form colonies within 7 days of incubation [3]. Although M. fortuitum is most commonly isolated from patients who are undergoing PD with peritonitis due to NTM [4], M. chelonae is also one of the most common RGNTM, which is associated with skin and soft tissue infections [3]. PD-associated catheter infections due to NTM might be underdiagnosed because they can be treated as refractory infections without identification of the organism. Prompt diagnosis is critical, particularly in cases of infections caused by RGNTM, because they rapidly progress, and exit site infection (ESI) is a major predisposing factor for peritonitis [5]. A 5year retrospective study in a large single-center multi-ethnic Asian population revealed that RGNTM accounted for $3 \%$ of ESIs and PD-associated peritonitis with a high rate of catheter loss $(80 \%)$ and increased 3-month mortality rate (40\%) [2]. Moreover, infections caused by RGNTM are usually difficult to treat due to their resistance to commonly used antibiotics [6] and lack of definitive guidelines regarding the treatment of PD-associated catheter infection due to RGNTM. To promptly identify NTM, acid-fast staining should be considered if the infection is not well-controlled. Here, we present a case of ESI caused by M. chelonae infection in an elderly patient on PD. The infection was rapidly diagnosed by acid-fast staining and successfully treated with catheter removal and followed by catheter reinsertion. It is important to consider the risk of NTM infections in patients with PD-associated catheter infections.

\section{Case Report}

A 70-year-old Japanese man who had been on continuous ambulatory PD (CAPD) for 2 years and with suspected ESI was admitted to our hospital. PD was initiated due to an endstage kidney disease caused by diabetic nephropathy. His daily PD exchange protocol consisted of 3 cycles of $2.0 \mathrm{~L}$ of $1.5 \%$ glucose-based solutions (dwell time, $4 \mathrm{~h}$ each) and 1 cycle of $2.0 \mathrm{~L}$ of $7.5 \%$ icodextrin-based solution (dwell time, $12 \mathrm{~h}$ ). PD was chosen as a modality of 


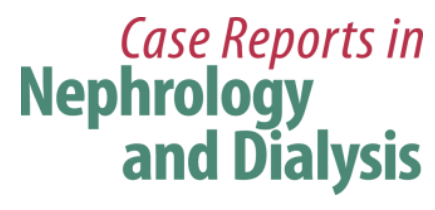

Case Rep Nephrol Dial 2018;8:1-9

DOI: 10.1159/000486159

(c) 2018 The Author(s). Published by S. Karger AG, Basel www.karger.com/cnd

Hibi et al.: Exit Site Infection due to Mycobacterium chelonae in an Elderly Patient on Peritoneal Dialysis

renal replacement therapy because the patient did not have suitable indications for hemodialysis (HD) due to low cardiac function (ejection fraction, 20\%) and a history of atrial fibrillation and myocardial infarction. He had also experienced 2 episodes of tunnel infection caused by methicillin-resistant Staphylococcus aureus at 8 and 4 months prior to admission, which were successfully treated with intravenous vancomycin. Surgery for translocation of the exit site to be created at the left upper abdomen was performed at the initial ESI. After the initiation of PD, an ointment containing bacitracin and fradiomycin sulfate was used for exit site care. During this period, the patient noticed an increased amount of pus discharge from the exit site 1 week prior to admission. At initial presentation, the patient was afebrile and asymptomatic. His vital signs included a body temperature of $36.2^{\circ} \mathrm{C}$, blood pressure of $114 / 65 \mathrm{~mm} \mathrm{Hg}$, heart rate of 73 beats/min with irregular rhythm, respiratory rate of 16 breaths/min, and oxygen saturation of $99 \%$ with room air. On physical examination, swelling and induration around the exit site and purulent discharge from the exit site were noted (Fig. 1). Subcutaneous fluid accumulation localized around the exit site was observed on ultrasound and computed tomography (Fig. 2). Peritoneal fluid analysis revealed a slightly elevated white blood cell count of $57 / \mu \mathrm{L}$ (monocytes, 60\%; polynuclear leukocytes, $40 \%$ ), but aerobic and anaerobic cultures were negative. Blood tests revealed a white blood cell count of $4,800 / \mu \mathrm{L}$, red blood cell count of $505 \times 10^{4} / \mu \mathrm{L}$, hemoglobin level of $11.7 \mathrm{~g} / \mathrm{dL}$, platelet count of $12.1 \times 10^{4} / \mu \mathrm{L}$, and C-reactive protein level of $3.63 \mathrm{mg} / \mathrm{dL}$. He was diagnosed with recurrent ESI. Although incision and drainage of the exit site were not performed, intravenous vancomycin was initiated from the day of admission because methicillin-resistant $S$. aureus was initially suspected as the causative organism. However, Gram staining of the pus did not reveal any gram-positive cocci. Instead, weakly stained grampositive rods were observed on day 7 , and the sample was positive on acid-fast staining performed on the same day (Fig. 3). RGNTM were suspected as the causative organism, and antibiotics were switched to a combination therapy of clarithromycin, amikacin, and imipenem/cilastatin on the same day. Mycobacterium culture using BD MGITTM tubes (Nippon Becton Dickinson Company, Fukushima, Japan) was performed on day 7, and M. chelonae was detected using DNA-DNA hybridization (DDH Mycobacterium "Kyokuto," Kyokuto Pharmaceutical Industrial Co., Ltd., Tokyo, Japan) on day 15. Because the amount of the pus did not decrease despite the antibiotic therapy, we consulted urologists in our hospital, and catheter removal surgery was performed on day 21. Mycobacterium cultures of the tip, first cuff, and second cuff of the PD catheter were all negative. These results almost ruled out the possibility of comorbid peritonitis and tunnel infection. After catheter removal, the patient's condition was stable, and he did not require HD because his urine volume was conserved. Moreover, he did not manifest any uremic symptoms even after the discontinuation of PD. After the surgery, antibiotic therapy was reinitiated, and catheter reinsertion surgery was performed on day 48 by stepwise initiation of PD using the Moncrief and Popovich technique, considering the risk of recurrent infection. The antibiotic regimen was switched to oral clarithromycin, faropenem, and levofloxacin on the same day. The exit site was made on day 61, and CAPD was reinitiated without complications. The patient was discharged on day 65. Although M. chelonae isolated from the patient was resistant to almost all types of antibiotics (Table 1), antibiotic therapy was continued for 3 months after discharge. The patient was able to continue CAPD after the discontinuation of antibiotics, and no indications for any recurrent infections were observed 1 year after discharge. 


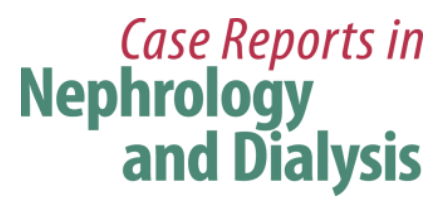

Case Rep Nephrol Dial 2018;8:1-9

DOI: $10.1159 / 000486159$

(C) 2018 The Author(s). Published by S. Karger AG, Basel www.karger.com/cnd

Hibi et al.: Exit Site Infection due to Mycobacterium chelonae in an Elderly Patient on Peritoneal Dialysis

\section{Discussion}

M. chelonae is classified in the M. chelonae-abscessus group in RGNTM, and M. chelonae and M. abscessus were considered identical until 1992 due to overlapping biochemical and genetic properties [3]. M. chelonae is ubiquitously isolated from natural environments and usually causes skin and soft tissue infections, postsurgical and posttraumatic wound infections, and catheter-related infections [3, 6]. Ando et al. [7] reported reduced synthesis of cytokines and impaired maturation of helper T cells in vitro in patients on PD compared to those on HD, suggesting the susceptibility of patients on PD to infections. Based on experimental studies, Hall-Stoodley et al. [8] reported that M. chelonae formed a biofilm on silicone rubber and high-density polyethylene surfaces under high- and low-nutrient conditions. We could not find any study describing biofilm formation on a PD catheter due to M. chelonae infection. However, biofilm formation on the PD catheter might contribute to the high rate of catheter loss in patients with PD-associated catheter infections caused by NTM.

M. chelonae is one of the most antibiotic-resistant species of pathogenic RGNTM [3]. The American Thoracic Society has described the antibiotic susceptibilities of RGNTM [6]. However, M. chelonae isolated from the present case was highly resistant to commonly used antibiotics. Hatakeyama et al. [9] studied the antibiotic susceptibility of RGNTM in Japan and reported that all $M$. chelonae strains isolated were susceptible to clarithromycin and linezolid. Tigecycline, the first commercially available glycylcycline, may be effective against multidrug resistant RGNTM, regardless of the species [9]. However, tigecycline has not been approved for use in NTM infections in Japan.

Exit site care may be an important factor in preventing ESIs. However, there is no definite exit site care protocol for significantly reducing ESIs due to NTM. Recently, Okado et al. [10] reported the effectiveness of a local thermal therapy using disposable pocket warmers for treating ESIs due to $M$. chelonae in addition to combined antibiotic therapy and exit site cleaning with $10 \%$ povidone-iodine solution; in this case, the patient was successfully treated without catheter removal. Local thermal therapy might be effective for treating ESIs because $M$. chelonae prefers lower temperatures and grows best at $30^{\circ} \mathrm{C}[3]$. Further clinical studies are necessary to prevent ESIs due to NTM and provide better exit site care for patients with NTM infections on PD.

Song et al. [4] reviewed 57 cases of PD-associated NTM peritonitis and reported that $M$. chelonae was the second most prevalent causative organism of NTM peritonitis $(14.0 \%)$, following M. fortuitum (38.6\%). Importantly, unresponsiveness to antibiotics contributed to the high rate of catheter removal (92.9\%). Kunin et al. [11] reviewed 11 cases of PDassociated peritonitis due to $M$. chelonae, including their own case, and reported that ESI was diagnosed in 4 cases (36\%) and catheter removal was performed in $10(90 \%)$. We identified 5 previously reported cases of ESI caused by M. chelonae in the literature (ESIs with comorbid peritonitis were excluded) $[10,12-14]$. Including the present case, catheter removal was performed in 4 cases (67\%), and 4 cases ( 2 patients required catheter reinsertion but the other 2 did not) were able to continue PD (67\%) (Table 2). Compared with peritonitis due to M. chelonae infection, ESI or tunnel infection due to M. chelonae can be well controlled and treated by catheter removal and antibiotic therapy, followed by catheter reinsertion. In the present case, combination antibiotic therapy was not effective, and catheter removal was required. However, we successfully treated the patient through catheter reinsertion without 


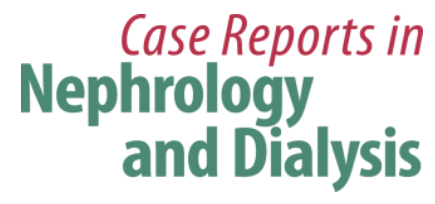

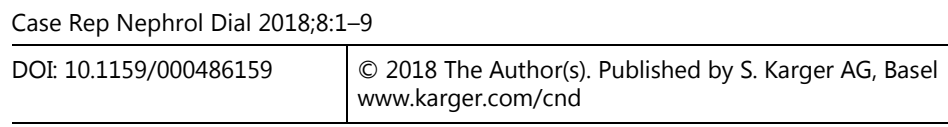

Hibi et al.: Exit Site Infection due to Mycobacterium chelonae in an Elderly Patient on Peritoneal Dialysis

recurrence of the infection. We considered that prompt catheter removal and allowing sufficient time between the catheter removal and PD reinitiation with antibiotic therapy might contribute to the prevention of recurrent infections.

Importantly, the acid-fast staining assay was inexpensive and useful for prompt diagnosis. We previously reported a case of ESI and comorbid tunnel infection due to M. abscessus, where acid-fast staining contributed to a prompt and precise diagnosis [15]. Prompt diagnosis of NTM infections is important because progression to peritonitis can be fatal. PDassociated catheter infections due to NTM are critical, especially for patients who cannot tolerate HD due to medical reasons, such as low cardiac functions and hypotension during HD.

\section{Conclusion}

NTM are rare catheter-associated infections in patients on PD. However, they can lead to catheter loss and be life-threatening. Refractory PD catheter-associated infections caused by NTM may be underdiagnosed. Considering the risk of NTM infections in patients on PD, acidfast staining assays and mycobacterium cultures should be performed when weakly stained gram-positive rods are observed on Gram staining but bacterial cultures are negative. Although acid-fast staining is not routinely performed in cases where PD-associated catheter infections are suspected, it was a key test for prompt diagnosis and appropriate treatment in the present case.

\section{Acknowledgements}

We are grateful to the clinical microbiology technicians of Kariya Toyota General Hospital, Aichi, Japan, who support our daily clinical practice.

\section{Statement of Ethics}

The authors have no ethical conflicts to declare.

\section{Disclosure Statement}

The authors declare no conflicts of interest. 
Hibi et al.: Exit Site Infection due to Mycobacterium chelonae in an Elderly Patient on Peritoneal Dialysis

\section{References}

1 Akoh JA: Peritoneal dialysis associated infections: an update on diagnosis and management. World J Nephrol 2012;1:106-122.

2 Renaud CJ, Subramanian S, Tambyah PA, Lee EJ: The clinical course of rapidly growing nontuberculous mycobacterial peritoneal dialysis infections in Asians: a case series and literature review. Nephrology (Carlton) 2011;16:174-179.

3 Brown-Elliott BA, Wallace RJ Jr: Clinical and taxonomic status of pathogenic nonpigmented or latepigmenting rapidly growing mycobacteria. Clin Microbiol Rev 2002;15:716-746.

$\checkmark 4$ Song Y, Wu J, Yan H, Chen J: Peritoneal dialysis-associated nontuberculous mycobacterium peritonitis: a systemic review of reported cases. Nephrol Dial Transplant 2012;27:1639-1644.

$\$ 5$ Van Diepen AT, Tomlinson GA, Jassal SV: The association between exit site infection and subsequent peritonitis among peritoneal dialysis patients. Clin J Am Soc Nephrol 2012;7:1266-1271.

6 Griffith DE, Aksamit T, Brown-Elliott BA, Catanzaro A, Daley C, Gordin F, Holland SM, Horsburgh R, Huitt G, Iademarco MF, Iseman M, Olivier K, Ruoss S, von Reyn CF, Wallace RJ Jr, Winthrop K; ATS Mycobacterial Diseases Subcommittee; American Thoracic Society; Infectious Disease Society of America: An official ATS/IDSA statement: diagnosis, treatment, and prevention of nontuberculous mycobacterial diseases. Am J Respir Crit Care Med 2007;175:367-416.

7 Ando M, Shibuya A, Yasuda M, Azuma N, Tsuchiya K, Akiba T, Nitta K: Impairment of innate cellular response to in vitro stimuli in patients on continuous ambulatory peritoneal dialysis. Nephrol Dial Transplant 2005;20:2497-2503.

-8 Hall-Stoodley L, Keevil CW, Lappin-Scott HM: Mycobacterium fortuitum and Mycobacterium chelonae biofilm formation under high and low nutrition conditions. J Appl Microbiol 1998;85:60S-69S.

-9 Hatakeyama S, Ohama Y, Okazaki M, Nukui Y, Moriya K: Antimicrobial susceptibility testing of rapidly growing mycobacteria isolated in Japan. BMC Infect Dis 2017;17:197.

10 Okado T, Iimori S, Nishida H, Yui N, Sohara E, Rai T, Uchida S, Sasaki S: Successful treatment of Mycobacterium chelonae peritoneal dialysis-related infection by a combination regimen including local thermal therapy. Perit Dial Int 2015;35:114-116.

11 Kunin M, Knecht A, Holtzman EJ: Mycobacterium chelonae peritonitis in peritoneal dialysis. Literature review. Eur J Clin Microbiol Infect Dis 2014;33:1267-1271.

12 Gehr TW, Walters BA: Catheter-related Mycobacterium chelonei infection in a CAPD patient. Perit Dial Int 1994;14:278-279.

13 Siu YP, Leung KT, Tong MK, Lee MK: Mycobacterium chelonae exit site infection in a patient on peritoneal dialysis. Clin Nephrol 2005;63:321-324.

14 Tse KC, Lui SL, Cheng VC, Yip TP, Lo WK: A cluster of rapidly growing mycobacterial peritoneal dialysis catheter exit-site infections. Am J Kidney Dis 2007;50:e1-e5.

15 Hibi A, Kasugai T, Kamiya K, Kamiya K, Kominato S, Mizuguchi K, Miura T, Koyama K: Peritoneal dialysis-associated catheter infection caused by Mycobacterium abscessus in an elderly patient who was successfully treated with catheter removal. CEN Case Rep 2017;6:175-179. 


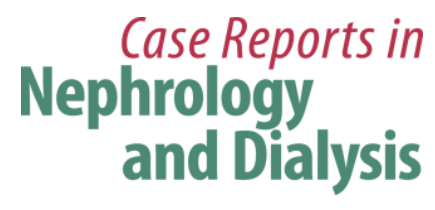

Case Rep Nephrol Dial 2018;8:1-9

DOI: $10.1159 / 000486159$

Hibi et al.: Exit Site Infection due to Mycobacterium chelonae in an Elderly Patient on Peritoneal Dialysis

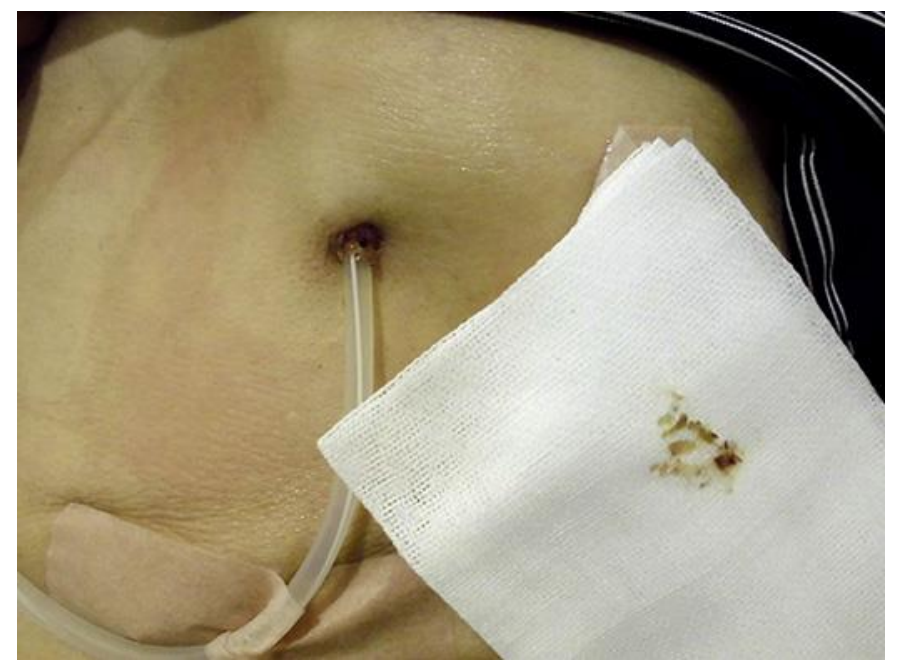

Fig. 1. Appearance of the exit site on the day of admission. There is a crust around the exit site, and subcutaneous tissue is swollen. Discharged pus is adhering to the gauze.
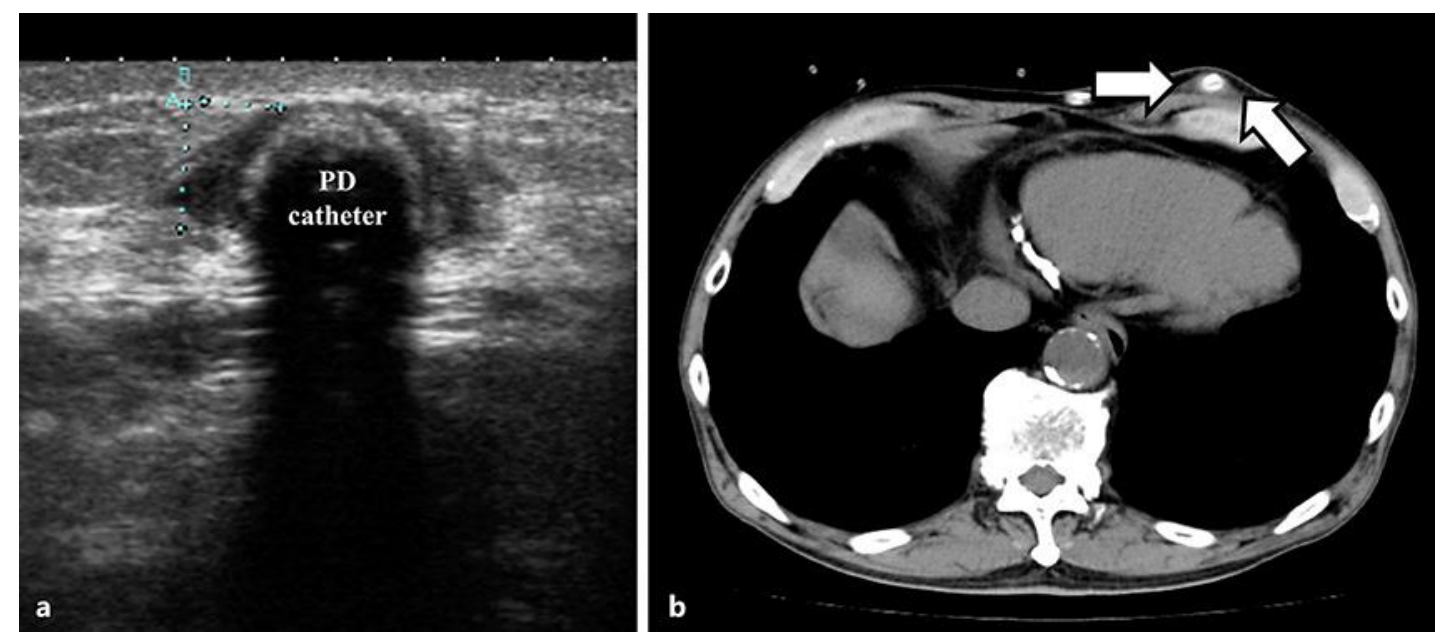

Fig. 2. Ultrasound and computed tomography (CT) evaluation on the day of admission. a Fluid accumulation, which indicates abscess formation, is observed in the subcutaneous tissue near the exit site on ultrasound. b Fluid accumulation is also confirmed on CT images (arrows). No sign of tunnel infection is observed. PD, peritoneal dialysis. 

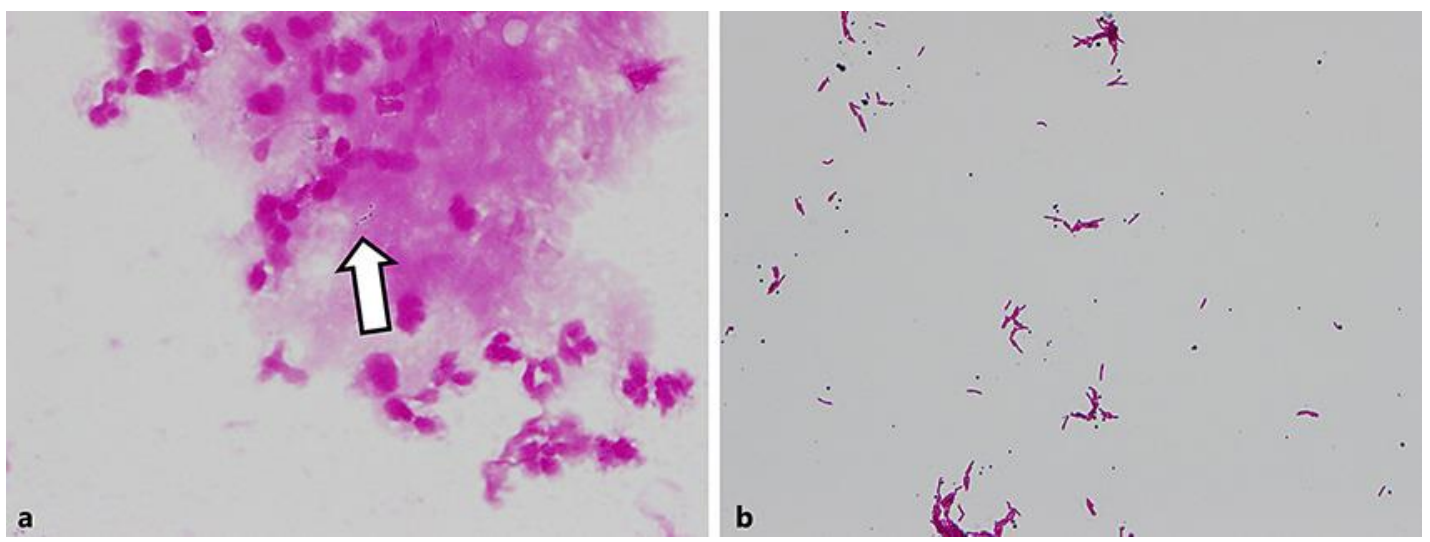

Fig. 3. Gram staining and acid-fast staining of the pus collected on the day of admission (magnification, $\times 1,000$ ). a Weakly stained gram-positive rods are observed with Gram staining (arrow). b Acid-fast bacilli are observed with acid-fast staining.

Table 1. Antibiotic susceptibilities of Mycobacterium chelonae isolated from the present case

\begin{tabular}{lll}
\hline Antibiotics & $\begin{array}{c}\text { Drug concen- } \\
\text { tration, } \mu \mathrm{g} / \mathrm{mL}\end{array}$ & Susceptibilitya \\
\hline SM & 10 & $\mathrm{R}$ \\
PAS & 0.5 & $\mathrm{R}$ \\
INH & $0.2 / 1.0$ & $\mathrm{R} / \mathrm{R}$ \\
RFP & 40 & $\mathrm{R}$ \\
TH & 20 & $\mathrm{R}$ \\
KM & 20 & $\mathrm{R}$ \\
EVM & 20 & $\mathrm{R}$ \\
EB & 2.5 & $\mathrm{R}$ \\
CS & 30 & $\mathrm{R}$ \\
LVFX & 1.0 & $\mathrm{R}$ \\
\hline
\end{tabular}

SM, streptomycin; PAS, p-aminosalicylic acid; INH, isoniazid; RFP, rifampicin; TH, ethionamide; KM, kanamycin; EVM, enviomycin; EB, ethambutol; CS, cycloserine; LVFX, levofloxacin; R, resistant.

a Antibiotic susceptibilities were determined by the proportion method using Vite Spectrum SR

(Kyokuto Pharmaceutical Industrial Co., Ltd., Tokyo, Japan). 


\section{Case Reports in Nephrology and Dialysis}

\begin{tabular}{l|l} 
Case Rep Nephrol Dial 2018;8:1-9 \\
\hline DOI: 10.1159/000486159 & $\begin{array}{l}\text { (C) } 2018 \text { The Author(s). Published by S. Karger AG, Basel } \\
\text { www.karger.com/cnd }\end{array}$ \\
\hline
\end{tabular}

Hibi et al.: Exit Site Infection due to Mycobacterium chelonae in an Elderly Patient on Peritoneal Dialysis

Table 2. Previously reported cases of exit site infections caused by Mycobacterium chelonae and the present case

\begin{tabular}{|c|c|c|c|c|c|c|c|c|c|c|c|c|}
\hline $\begin{array}{l}\text { Case } \\
\text { No. }\end{array}$ & $\begin{array}{l}\text { Reported } \\
\text { year }\end{array}$ & Reference & $\begin{array}{l}\text { Age/ } \\
\text { sex }\end{array}$ & $\begin{array}{l}\text { Underly- } \\
\text { ing } \\
\text { disease }\end{array}$ & $\begin{array}{l}\text { PD } \\
\text { modality }\end{array}$ & $\begin{array}{l}\text { Duration } \\
\text { of PD }\end{array}$ & $\begin{array}{l}\text { Previous } \\
\text { history } \\
\text { of ESI }\end{array}$ & $\begin{array}{l}\text { Tunnel } \\
\text { infection }\end{array}$ & $\begin{array}{l}\text { Initial antibi- } \\
\text { otics treatment } \\
\text { (duration) }\end{array}$ & $\begin{array}{l}\text { Definitive } \\
\text { antibiotics } \\
\text { treatment } \\
\text { (duration) }\end{array}$ & Catheter removal & Clinical outcome \\
\hline Case 1 & 1994 & [12] & $40 / \mathrm{M}$ & ADPKD & CAPD & 4 months & no & yes & $\begin{array}{l}\text { oral } \\
\text { dicloxacillin } \\
\text { (4 weeks) } \\
\text { and IP VCM } \\
\text { (3 weeks) }\end{array}$ & $\begin{array}{l}\text { oral CPFX } \\
\text { (8 weeks) }\end{array}$ & yes & $\begin{array}{l}\text { cadaveric } \\
\text { kidney } \\
\text { transplant } \\
\text { after catheter } \\
\text { removal }\end{array}$ \\
\hline Case 2 & 2005 & [13] & $60 / \mathrm{M}$ & $\mathrm{DM}$ & CAPD & 3 months & no & yes & $\begin{array}{l}\text { oral LVFX } \\
\text { (1 week) }\end{array}$ & $\begin{array}{l}\text { IP AMK and } \\
\text { oral CAM } \\
\text { (14 weeks) }\end{array}$ & $\begin{array}{l}\text { no (exteriorization } \\
\text { and shaving of the } \\
\text { outer cuff were } \\
\text { performed, followed } \\
\text { by local thermal } \\
\text { therapy) }\end{array}$ & $\begin{array}{l}\text { continued } \\
\text { CAPD }\end{array}$ \\
\hline Case 3 & 2007 & {$[14]$} & $40 / \mathrm{M}$ & IgAN & CAPD & 10 years & yes & no & $\begin{array}{l}\text { oral LVFX } \\
\text { (4 weeks) }\end{array}$ & $\begin{array}{l}\text { IV AMK and } \\
\text { oral CAM } \\
\text { ( } 6 \text { weeks) }\end{array}$ & yes & $\begin{array}{l}\text { converted to } \\
\text { HD } \\
\text { due to failed } \\
\text { catheter } \\
\text { reinsertion }\end{array}$ \\
\hline Case 4 & 2007 & [14] & $76 / \mathrm{M}$ & SLE & CAPD & 7 years & yes & yes & $\begin{array}{l}\text { IV AMK } \\
\text { (2 weeks), } \\
\text { followed by } \\
\text { IV CTRX } \\
\text { (1 week) }\end{array}$ & $\begin{array}{l}\text { IV AMK and } \\
\text { oral CAM } \\
\text { (10 weeks) }\end{array}$ & $\begin{array}{l}\text { yes (debridement } \\
\text { was performed } \\
\text { prior to catheter } \\
\text { removal) }\end{array}$ & $\begin{array}{l}\text { continued } \\
\text { CAPD by } \\
\text { catheter } \\
\text { reinsertion }\end{array}$ \\
\hline Case 5 & 2015 & [10] & $59 / \mathrm{M}$ & MN & APD & 3 years & no & no & $\begin{array}{l}\text { oral LVFX } \\
(9 \text { weeks in } \\
\text { total })\end{array}$ & $\begin{array}{l}\text { oral CAM, } \\
\text { RFP, and EB } \\
\text { (3 weeks) }\end{array}$ & $\begin{array}{l}\text { no (local thermal } \\
\text { therapy was } \\
\text { performed) }\end{array}$ & continued PD \\
\hline Case 6 & the prese & nt case & $70 / \mathrm{M}$ & $\begin{array}{l}\text { DM } \\
\text { CHF } \\
\text { OMI }\end{array}$ & CAPD & 2 years & yes & no & $\begin{array}{l}\text { IV VCM } \\
\text { (1 week) }\end{array}$ & $\begin{array}{l}\text { oral CAM, IV } \\
\text { AMK, and } \\
\text { IPM/CS } \\
\text { ( } 8 \text { weeks), } \\
\text { followed by oral } \\
\text { CAM, FRPM, } \\
\text { and LVFX } \\
\text { (15 weeks) }\end{array}$ & yes & $\begin{array}{l}\text { continued } \\
\text { CAPD by } \\
\text { catheter } \\
\text { reinsertion }\end{array}$ \\
\hline
\end{tabular}

M, male; ADPKD, autosomal dominant polycystic kidney disease; DM, diabetes mellitus; IgAN, immunoglobulin A nephropathy; SLE, systemic lupus erythematosus; MN, membranous nephropathy; CHF, congestive heart failure; OMI, old myocardial infarction; PD, peritoneal dialysis; CAPD, continuous ambulatory peritoneal dialysis; APD, automated peritoneal dialysis; ESI, exit site infection; IP, intraperitoneal; VCM, vancomycin; LVFX, levofloxacin; IV, intravenous; AMK, amikacin; CTRX, ceftriaxone; CPFX, ciprofloxacin; CAM, clarithromycin; RFP, rifampicin; EB, ethambutol; IPM/CS, imipenem/cilastatin; FRPM, faropenem; HD, hemodialysis. 